\title{
Effect of Accreditation on Awareness and Knowledge of Technicians about Laboratory Quality Measures in Tertiary Care Hospital
}

\author{
Pradnya Hemant Padalkar ${ }^{1}$, Rajni Rajendra Shivkar², Meghana Khandu Padwal ${ }^{3}$
}

\begin{abstract}
The advantage of Accreditation is quality test reports and customer satisfaction. Technicians are integral part of medical testing laboratories. So they should have commitment towards acquiring and updating sound knowledge about good laboratory practices.

Aim: To assess the impact of accreditation on awareness and knowledge of technician's about laboratory quality measures in tertiary care hospital. Material and Method: We prepared a questionnaire based on quality management system (QMS), Pre-Analytical, Analytical, Post-analytical examination and laboratory safety. Total thirty technicians appeared for pretest before accreditation, followed by various training sessions and NABL accreditation. A post test was conducted after accreditation for the same.

Result: The data of pretest and post-test performance was analyzed by SPSS software. The result shows there was significant $(p<0.001)$ increase in the score of the marks among technicians in post-test $(20.67 \pm 3.67)$ compared to pre-test $(10.21 \pm 4.39)$.

Conclusion: In present study we observed suboptimal knowledge \& awareness in technicians regarding QMS. This was found enhanced after Accreditation process \& continuous training sessions. This will be helpful to improve their skill to sustain quality laboratory services. Keyword: Accreditation, Awareness, Knowledge, Quality

Indian Journal of Medical Biochemistry (2019): 10.5005/jp-journals-10054-0099
\end{abstract}

\section{INTRODUCTION}

In today's practicing era of medicine, laboratory plays pivotal role in screening and management of diseases. It is moral duty of laboratory personnel to issue quality reports which fulfil customer's expectation. Accreditation by third party gives confidence to the client about accuracy and reliability of test reports leading to customer satisfaction. Accreditation process approves medical testing laboratory for their demonstrated capability and competence in every operational process, as it checks laboratory's compliance with pre-established standards. ${ }^{1-3}$ Accreditation can improve the quality of healthcare through the reduction of testing errors and decrease in repeat testing which is cost effective also for the laboratory. ${ }^{4}$ Thus to trigger and coordinate efforts to improve quality of our laboratory services we have undergone NABL accreditation programme in March 2017. Technicians, being fieldworkers in the lab they form integral part of medical laboratories. So they must have commitment towards acquiring and updating sound knowledge about good laboratory practices. ${ }^{5}$

There are few studies showing impact of accreditation on technician's knowledge and laboratory services in India. So present study was designed to assess the knowledge and awareness of technicians about laboratory processes followed in our hospital.

\section{Materials and Methods}

The present study was conducted at Bharati hospital and research Centre (BHRC) Pune. Thirty technicians of laboratory from different sections (Biochemistry, pathology and microbiology) were chosen to conduct their pretest and posttest. Technicians who have completed their DMLT post graduate course from authorized

\footnotetext{
${ }^{1,2}$ Assistant Professor, ${ }^{3}$ Professor and Head

${ }^{1-3}$ Department of Biochemistry, Bharati Vidyapeeth Deemed University Medical College, Pune, Maharashtra, India
}

Corresponding Author: Rajni Rajendra Shivkar, Assistant Professor, Department of Biochemistry, Bharati Vidyapeeth Deemed University Medical College, Pune, Maharashtra, India, e-mail: dr.rajni26@gmail. com

How to cite this article: Padalkar PH, Shivkar RR, Padwal MK. Effect of Accreditation on Awareness and Knowledge of Technicians about Laboratory Quality Measures in Tertiary Care Hospital. Indian J Med Biochem 2019;23(2):259-262.

Source of support: Nil

Conflict of interest: None

college and university were included in the study group. We prepared a questionnaire based on quality management system (QMS), Quality Control (QC), Pre-Analytical (PreAP), Analytical $(\mathrm{AP})$, Post-analytical procedures (PostAP) and laboratory safety by referring NABL 112, NABH guidelines and safety manual of Bharti Hospital Pune. Content validation method was used to validate questionnaire by total seven people (Two persons from Quality Cell of Bharati Hospital, Quality manager of laboratory, Lab in-charge of laboratory, one person from Infection control committee, Professor and Head of Microbiology and Pathology) from quality assurance cell and subject expertise of Bharati Hospital. These seven people have been working as subject expertise in respective fields for more than 15 years. For content validation of proposed questionnaire, copy of our questionnaire was given to each one of the expert and they were asked to give the comments about any improvements or change if needed. The necessary changes recommended by them were implemented and the questionnaire was validated.

(0) The Author(s). 2019 Open Access This article is distributed under the terms of the Creative Commons Attribution 4.0 International License (https://creativecommons. org/licenses/by-nc/4.0/), which permits unrestricted use, distribution, and non-commercial reproduction in any medium, provided you give appropriate credit to the original author(s) and the source, provide a link to the Creative Commons license, and indicate if changes were made. The Creative Commons Public Domain Dedication waiver (http://creativecommons.org/publicdomain/zero/1.0/) applies to the data made available in this article, unless otherwise stated. 
We planned pre-test before accreditation, followed by various training sessions by the laboratory faculty (who have completed internal auditor course) and process of NABL Accreditation, a posttest was conducted after accreditation for the same. The data of pretest \& post-test performance was analyzed by SPSS software. Paired

"t test" was applied for comparing performance of technicians in Pre-test and post-test. $P$ value of $<0.05$ was taken as statistically significant.

The present study was approved by the institutional ethical committee. After informed written consent questionnaire was given to the participants which is as follows.

Bharati Vidyapeeth University Medical College, Hospital and Research Centre, Laboratory, Pune-43

Name of Technician:

Day and Date:

Marks:

\section{A. Quality Management System}

1. What is the full form of NABL?

2. Which clause comes under technical category for ISO 15189: 2012?

3. Which environmental conditions should be monitored to maintain the quality of any examinations in the laboratory?

4. What is the procedure \& frequency of cleaning of refrigerator and centrifuge?

5. From which document control file you will get information of number of stored or retained samples?

6. In which document control file will you get information about linearity of parameters measured in our lab?

7. Sample collection prerequisites are available in which manual and where is it located?

8. What are the parameters in the NABL scope of the laboratory?

\section{B. Quality Control}

9. What do you mean by 1:2s error in IQC (Internal Quality Control) policy?

10. What will be your plan of action if you realize that L2 (Low level control) is over?

11. What do you write on aliquots/ reagent bottles when you reconstitute new control or open new reagent?

12. Which EQAS (External Quality Assurance Service) sample/s is/are run in your section?

13. What is frequency of IQC run in our lab?

\section{Pre Analytical Procedure}

14. How do we monitor appropriateness of test request form (TRF)?

15. What do you do with the container you receive from pneumatic shoot at your section?

16. What is the procedure to trace a lost sample in your section?

\section{Analytical Procedures}

17. If there is breakdown of equipment during your working hours. What will be your plan of action?

18. One day suddenly you find temperature of your reagent kit refrigerator (supposed to be $2-8^{\circ} \mathrm{C}$ ) displayed as $12^{\circ} \mathrm{C}$. What would you do?

19. Humidity of air is monitored by which instrument?
20. What is the first thing you do when you start any equipment and in which document control file record is maintained?

21. What is the prerequisite for using a kit with new lot number when old lot number kit is over?

\section{E. Post Analytical Procedure}

22. At what temperature should samples be retained as per standard 112 ?

23. If an abnormal value for a particular parameter in sample is obtained, what action will be taken?

F. Safety

24. Used gloves are discarded in which colored bag?

25. What is the percentage of Hypochlorite required for floor cleaning in the laboratory?

26. Which are steps for Hand hygiene?

27. Write the steps of blood spill management?

\section{ResULt}

In our study we observed there was marked increase in knowledge \& awareness of technicians in post-test conducted after accreditation $(21.1 \pm 3.6)$, which was statistically significant ( $p$ value $<0.001$ ) compared to pre-test $(11.3 \pm 5.2)$ as shown in Figure 1, Table 1.

We categorized total number of technicians into senior and junior based on their experience. Technicians working in the field of medical laboratory for more than 10 years were taken into senior technician's category while technician's with less than 10 years of experience were categorized as junior technicians.

We observed increase in performance of senior and junior technicians in post-test ( $21 \pm 5.5,21.3 \pm 4.1$ respectively) as compared to pre-test (12.1 $\pm 8.1,9.4 \pm 5.9$ respectively). Performance of junior and senior technicians were near to equal in post-test after accreditation but this comparison was not statistically significant ( $p$ value $>0.05$ ). [Figs 2 and 3; Tables 2 and 3]

\section{Discussion}

Accreditation ensures the adherence of the laboratory to the required quality and competence to achieve accurate and reliable test reports. Accreditation process help to identify the area that

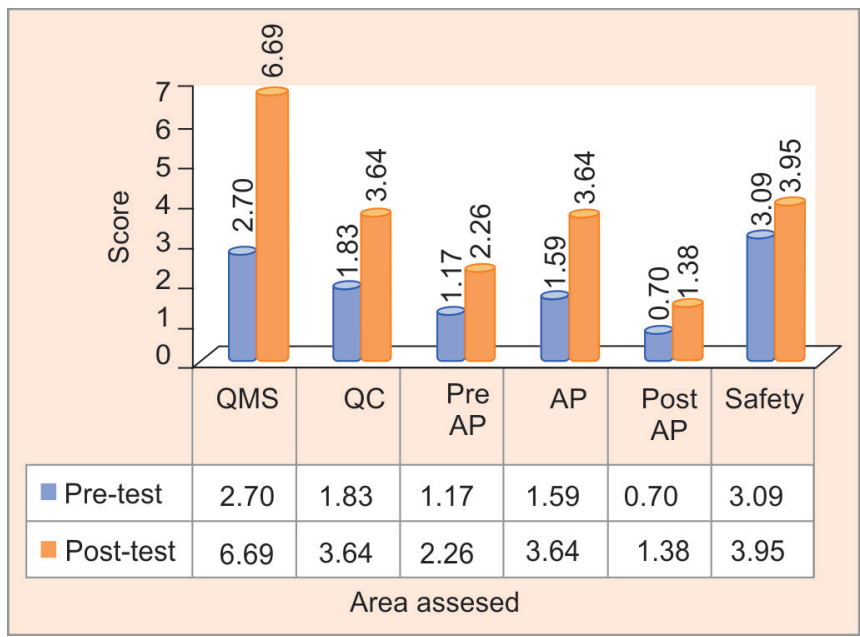

Fig. 1: Comparison of pre-test and post-test performance

Table 1: Pre-test and post-test performance of technicians

\begin{tabular}{lllllll}
\hline & QMS & QC & PreAP & AP & PostAP & Safety \\
\hline Pre-test (Mean \pm SD) & $2.70 \pm 1.98$ & $1.83 \pm 1.34$ & $1.17 \pm 0.96$ & $1.59 \pm 0.52$ & $0.70 \pm 0.22$ & $3.09 \pm 1.04$ \\
Post-test (Mean \pm SD) & $6.69 \pm 1.32$ & $3.64 \pm 1.24$ & $2.26 \pm 0.66$ & $3.64 \pm 1.13$ & $1.38 \pm 0.41$ & $3.95 \pm 0.21$ \\
\hline
\end{tabular}




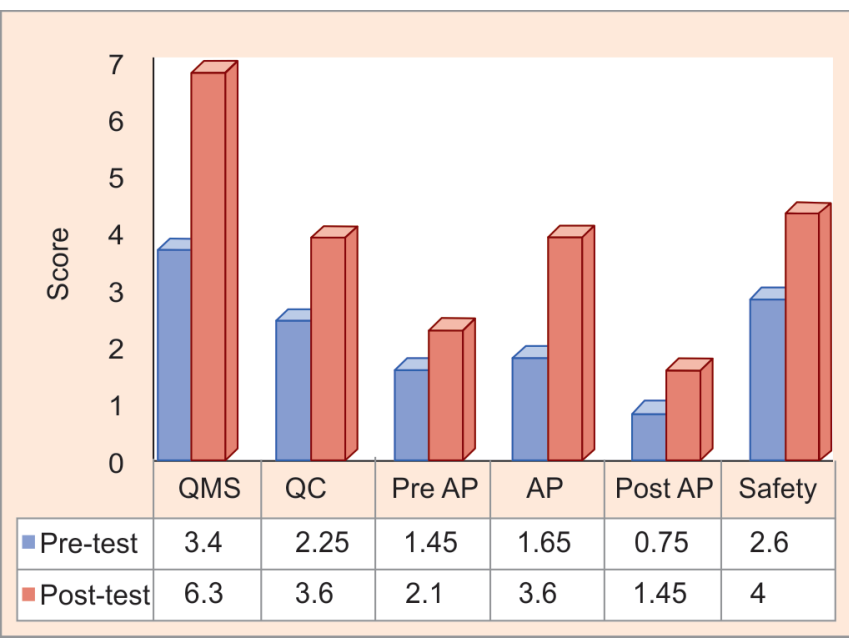

Fig. 2: Senior technician's performance in pre-test and post-test

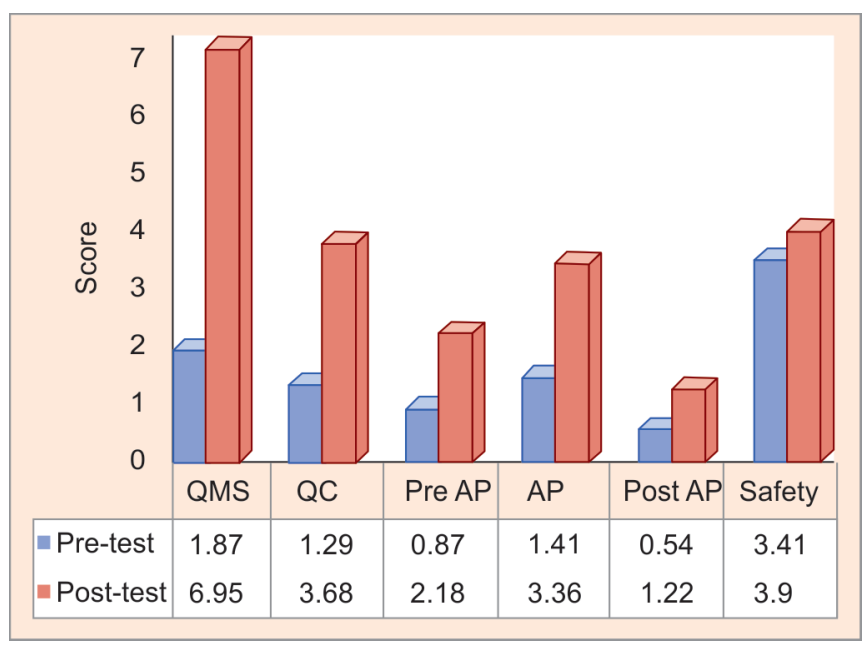

Fig. 3: Junior technician's performance in pre-test and post test

Table 2: Pre-test and Post-test performance of senior technicians

\begin{tabular}{lllllll}
\hline & QMS & QC & PreAP & AP & PostAP & Safety \\
\hline Pre-test (Mean \pm SD) & $3.4 \pm 1.98$ & $2.25 \pm 1.25$ & $1.45 \pm 1.14$ & $1.65 \pm 1.06$ & $0.75 \pm 0.19$ & $2.6 \pm 1.24$ \\
Post-test (Mean \pm SD) & $6.3 \pm 1.82$ & $3.6 \pm 1.26$ & $2.1 \pm 0.61$ & $3.6 \pm 1.34$ & $1.45 \pm 0.49$ & $4.0 \pm 0.01$ \\
\hline
\end{tabular}

Table 3: Pre-test and post-test performance of Junior Technicians

\begin{tabular}{lllllll}
\hline & QMS & QC & PreAP & AP & PostAP & Safety \\
\hline $\begin{array}{l}\text { Pre-test } \\
\text { (Mean } \pm \text { SD }\end{array}$ & $1.87 \pm 1.15$ & $1.29 \pm 1.09$ & $0.87 \pm 0.74$ & $1.41 \pm 1.24$ & $0.54 \pm 0.39$ & $3.41 \pm 0.70$ \\
$\begin{array}{l}\text { Post-test } \\
\text { (Mean } \pm \text { SD) }\end{array}$ & $6.95 \pm 0.35$ & $3.68 \pm 1.28$ & $2.18 \pm 0.87$ & $3.36 \pm 1.05$ & $1.22 \pm 0.26$ & $3.9 \pm 0.30$ \\
\hline
\end{tabular}

can be improved in the operation of laboratory that results in quality diagnostic services. Core of the accreditation process is the release of Sample collection manual, Quality Manual, Safety manual, Standard Operating Procedures (SOPs), Work instructions, Lab procedures followed in the laboratory to be documented and made available at the work stations. This whole process contributes to the improvement in the knowledge, skill, confidence and competency of the technicians which ultimately can lead to quality laboratory services. ${ }^{4}$

In present study we observed suboptimal knowledge and awareness in technicians regarding quality assurance standard. This was found enhanced after accreditation process and continuous training sessions (Figs 1 to 3 and Tables 1 to 3 ). Several studies have shown that accreditation programs significantly improve clinical outcomes and quality of test reports which finally contribute to continual improvement.

Abdullah Alkhenizan and Charles Shaw (2011) found in their study that accreditation programs improve the standard of care provided by healthcare services. $^{3}$

Senthilkumaran S (2014) conducted a study on Awareness and knowledge about external quality assurance among clinical Biochemistry laboratory technicians in a tertiary care hospital concluded that training sessions can enhance knowledge and competency skill among technicians and to deliver quality reports. ${ }^{2}$

Peter TF (2010) in their review article concluded that accredited laboratories can become more accountable and less dependent on external support. Further they said more studies should be carried out to strengthen the benefits of accreditation. ${ }^{4}$
MP Pomey and LL Charles study was similar to us, they chose Canadian health population but assessed small number of cases and their findings recommend accreditation. ${ }^{6}$

$\mathrm{S}$ Devkaran and Pattrick N O'Farrell examined impact of healthcare accreditation on hospital quality measures by survey and findings concludes as improvement achieved due to accreditation which is maintained till three year accreditation cycle. ${ }^{7}$

Our result has shown improvement in technician's performance by ensuring quality of pre-analytical, analytical and post - analytical examination process, thereby leading to increased accuracy of test results and reduced frequency of errors. Technician's positive impact about NABL process found to be helpful for giving standard services to the customer by informing critical values as early as possible leading to decreased turnaround time(TAT) and helping in clinical decision making to the treating physician. Our findings are supported by Jang, Yoon and etal. ${ }^{8}$ They studied effect of accreditation on accuracy of diagnostic tests in medical laboratories and have emphasized the necessity of establishing a system for standardization of diagnostic testing.

Our questionnaire included all the areas of laboratory which are sensitive to affect the quality of reports and we found accreditation programme has positive effect in technician's knowledge, operational efficiency and quality of customer services provided by the laboratory. Continuous training sessions, seminars, workshops on QMS, SOPs, work instructions which are integral part of Accreditation process encouraged our technicians to follow good laboratory practices which are core of laboratory services. 


\section{CONCLUSION}

Although accreditation process is voluntary in our country, should be encouraged to improve quality of healthcare services and reduce the frequency of errors. As we found in our study, Accreditation process has shown improvement in the knowledge of technicians about quality assurance. This led to better practices and attitude of them to follow standard procedures, to keep documentation of processes for continual improvement of patient care and motivated them to make efforts for customer satisfaction through quality laboratory services. Laboratories should make all efforts to implement robust training programs for all healthcare workers for their sustenance and improvement of skill and competency. Accreditation is not a one-step phenomenon but a continuous process.

\section{LIMITATION}

The study population was only from single laboratory which has undergone the process of accreditation with limited number of technicians.

\section{ACKNOWLedgments}

We are greatly thankful to Dr MS Modak, Lab Director and Dr Anjali Kelkar, Quality manager for allowing us to conduct this study in BHRC laboratory Pune. We are also thankful to quality assurance cell and Subject expertise for their valuable inputs in validation of questionnaire.

\section{References}

1. Manickam TS, Ankangari S. Evaluation of quality management systems implementation in medical diagnostic laboratories benchmarked for accreditation. Journal of medical laboratory \& diagnosis 2015; 6(5): 27-35.

2. Senthilkumaran S, Sunthia A, Sundharajan A. A study on awareness and knowledge about external quality assurance among clinical biochemistry laboratory technicians in a tertiary care hospital. Webmed Central Clinical Biochemistry 2014; 5(9): 1-7.

3. Alkhenizan A, Shaw C. Impact of accreditation on the quality of healthcare services: a systematic review of the literature. Annals of Saudi Medicine 2011; 31(4):407-416.

4. Peter TF, Rotz PD, Blair DH. Impact of laboratory accreditation on patient care and the health system.Am J Clin Pathol 2010;134:550555.

5. Henry M, Ojo E, Ameh J. Piloting laboratory quality system management in six health facilities in Nigeria. PLOS ONE.2014: 1-14

6. MP Pomey, LL Charles, Champagne F. Does accreditation stimulate change? A study of the impact of the accreditation process on Canadian healthcare organizations. Implementation Science. 2010; 5 (31):1-14.

7. Devkaran S, Pattrick N O'Farrell. The impact of hospital accreditation on quality measures: an interrupted time series analysis. BMC Health Services Research. 2015; 15 (137):1-14.

8. Mi-Ae Jang, Young Ahn Yoon, Junghan Song, Jeong-Ho Kim, Won-Ki Min and etal Effect of Accreditation on Accuracy of Diagnostic Tests in Medical Laboratories. Ann Lab Med. 2017 May; 37(3): 213-222. 